Original Article

\title{
DERMAL DELIVERY OF DOCETAXEL LOADED NANO LIQUID CRYSTALS FOR THE TREATMENT OF SKIN CANCER
}

\section{ARTI MAJUMDAR ${ }^{1,2}$, NIDHI DUBEY ${ }^{1}$, NITIN DUBEY ${ }^{3}$}

\author{
${ }^{1}$ School of Pharmacy, Devi Ahilya Vishwavidyalaya, Indore, India, ${ }^{2}$ Smriti College of Pharmaceutical Education, Indore, India, ${ }^{3}$ College of \\ Pharmacy, IPS Academy, Indore, India
}

Email: artijmajumdar10@gmail.com

Received: 19 Jun 2019, Revised and Accepted: 25 Jul 2019

\begin{abstract}
Objective: The aim of the present study is to develop docetaxel-loaded nano liquid crystals (NLCs) to enhanced and effective delivery of the drug to the skin cancer.

Methods: NLCs bearing docetaxel were prepared by an emulsification solvent diffusion method. The formulated NLCs were characterized for average particle size, polydispersity index (PDI) Zeta potential, entrapment efficiency and in vitro drug release study. The prepared formulations were studied for it's in vitro cell line and cell uptake study.

Results: It was revealed that the average size of NLCs was found $178.3 \pm 5.07$, PDI was 0.189 , percent entrapment efficiency was found $71.3 \pm 2.49$ and Zeta potential was found-17.3 \pm 2.4 . In vitro release determined by Franz diffusion cell was found $61.6 \pm 3.2 \%$ after $72 \mathrm{hr}$. 3-(4,5-Dimethylthiazol2-yl)-2,5-diphenyltetrazolium bromide (MTT) assay shows that Docetaxel loaded NLCs were giving more cytotoxicity as compared to the plain drug. The cell uptake study was found enhanced uptake of fluorescein isothiocyanate (FITC) loaded NLCs in comparison to plain FITC. Docetaxel and docetaxel-loaded NLCs showed $28.3 \pm 0.3$ and $39.3 \pm 1.3$ growth inhibition respectively after $48 \mathrm{~h}$ upon incubation at $0.5 \mu \mathrm{g} / \mathrm{ml}$ concentration $(\mathrm{p}<0.05)$.
\end{abstract}

Conclusion: The result of the studies was concluded that NLCs can be used as impending drug delivery system which may enhance the drug uptake and maintain the drug level for longer period of time and it is potential carrier system which can be used for the treatment of skin diseases like cancer.

Keywords: Docetaxel, NLCs, Cytotoxicity, Skin cancer, Cell uptake

(c) 2019 The Authors. Published by Innovare Academic Sciences Pvt Ltd. This is an open-access article under the CC BY license (http://creativecommons.org/licenses/by/4.0/) DOI: http://dx.doi.org/10.22159/ijap.2019v11i5.34621

\section{INTRODUCTION}

Melanoma, squamous cell carcinoma, and basal cell carcinoma are different types of skin cancer that are most commonly origin by extensive contact to sunlight and it is recognized by unwarranted propagation of these type of cells which generally results in damage of keratinocytes. Excessive UV exposure suppresses the expression of p53 suppressor gene, which plays a key role in the removal of sunburn cells and avoidance of basal cells transformation. Docetaxel used to treat a number of breast cancer, head and neck cancer, stomach cancer, prostate cancer, and non-small-cell lung cancer. It is the taxane family of medications. It works by disrupting the normal function of microtubules and thereby stopping cell division [1]. It may be used by itself or along with other chemotherapy medication. Common side effects include hair loss, low blood cell counts, numbness, and irregular breathing and muscle pains. Unwanted drug distributions or chemotherapeutic failure is the major reason behind these side effects and it is necessary to design a suitable drug delivery system and select a route of administration which overcomes above side effect by preventing the unwanted distribution of drug [2,3]. A need for the simple, safe and stable formulation is necessary. Nano Liquid Crystals (NLCs) are a novel drug delivery systems have properties and advantages like NLCs and lipid NLCs [5]. NLCs are non-toxic and can be prepared without the use of toxic materials [6]. They are capable to protect the drug molecules against degradation and provide sustained release pattern $[7,8]$. The topical administration of Docetaxel-loaded NLCs for skin cancer can be minimizing the side effects of Docetaxel and increase therapeutic effectiveness [3]. The nanosize of NLCs promotes drug absorption through the stratum corneum, it is the outermost barrier of epidermis that able to retard the drug penetration into the skin [9]. Aim of this study was to investigate and assess the potential of Docetaxel-loaded NLCs for the treatment of skin cancer using skin cancer cell line $[2,10,11]$.

\section{MATERIALS AND METHODS}

\section{Materials}

Docetaxel was obtained as a gift sample from Sun Pharma Pvt Ltd. Ahmadabad, India. Stearic acid was purchased from Himedia, Mumbai, India. Oleic acid was purchased from Loba Chemical, Mumbai, India. Tristearin, cholesterol, and soya PC were purchased from Sigma Aldrich, USA. Other chemicals and solvents were used of analytical reagent grade.

\section{Preparation of docetaxel loaded NLCs}

The docetaxel-loaded NLCs were prepared solvent diffusion melt dispersion techniques according to Selvamuthukumar et al., 2012 [12]. The lipid, stearic acid $(3.0 \% \mathrm{w} / \mathrm{v})$, oleic acid $(0.5 \% \mathrm{w} / \mathrm{v})$, tristearin $(1.0 \% \mathrm{w} / \mathrm{v})$, cholesterol $(0.75 \%)$ and soya phosphatidylcholine $(1.5 \% \mathrm{w} / \mathrm{v})$ were dissolved in $10 \mathrm{ml}$ of ethanol: acetone solvent system in a $250 \mathrm{ml}$ of beaker. Drug (docetaxel $20 \% \mathrm{w} / \mathrm{w}$ of lipid) was added to above mixture. The mixture was melted $70{ }^{\circ} \mathrm{C}$ to get a clear lipid phase. In a separate beaker, $60 \mathrm{ml}$ of double-distilled water containing tween 80 was stirred under magnetic stirrer and then heated at $70{ }^{\circ} \mathrm{C}$ with heating mental. The aqueous phase was maintained at $70^{\circ} \mathrm{C}$ and kept under the highspeed homogenizer (IKA T 25 digital ULTRA-TURRAX®, Germany) at $10000 \mathrm{rpm}$ to make microemulsion. The oil phase containing drug was added dropwise to the aqueous phase using preheated (at 70 ${ }^{\circ} \mathrm{C}$ ) hypodermic syringe. After $30 \mathrm{~min}$ of stirring, heating was stopped. Then $20 \mathrm{ml}$ of cold water was added dropwise to reduce the temperature of the dispersion. The dispersion was continuously stirred for $2 \mathrm{hr}$ to the removal of ethanol and acetone from the NLCs. After stirring the prepared formulation was lyophilized using Labconco freeze dryer (Labconco, Cascade Freezone Plus 4.5 L Benchtop Freeze dryer, USA) and stored at $2-8{ }^{\circ} \mathrm{C}$ until further used for characterization. 


\section{Preparation of gel base}

Carbopol 934 (1-3\%w/v) was accurately weighed and dispersed into double distilled water $(80 \mathrm{ml})$ in a beaker. This solution was stirred continuously at $800 \mathrm{rpm}$ for 1 hour and then $10 \mathrm{ml}$ of propylene glycol was added to this solution. The obtained slightly acidic solution was neutralized by dropwise addition of $0.05 \mathrm{~N}$ sodium hydroxide solutions, and again mixing was continued until gel becomes transparent. The volume of the gel was adjusted to 100 $\mathrm{ml}$ and then sonicated for $10 \mathrm{~min}$ on bath sonicator to remove air bubbles. Final pH of the gel base was adjusted to 6.5 [13]. The gel was also prepared with the plain drug by adding $10 \mathrm{mg}$ of drug and dispersed properly by following the same procedure given above. The same procedure was used to formulate nanocarriers containing gel in which previously prepared NLCs were added in place of plain drug. The NLCs preparation corresponding to $6.0 \% \mathrm{w} / \mathrm{w}(6.0 \mathrm{mg}$ of drug in $100 \mathrm{mg}$ of gel) of the drug was incorporated into the gel base to get the desired concentration of drug in a gel base.

\section{Characterizations of docetaxel-loaded NLCS}

\section{Determination of particle size, PDI and surface charge}

Mean particle size distribution of Docetaxel-NLCs formulations and polydispersity index (PDI) of the NLCs were determined by photon correlation spectroscopy using a Zetasizer DTS, version 4.10 (Malvern Instrument, UK). Before analysis, the formulations were diluted with $1: 9 \mathrm{v} / \mathrm{v}$ with deionized water. The particles size and PDI were represented by the average diameter of the Gaussian distribution function in the logarithmic axis mode. Surface charge measurement of the NLCs was based on the zeta potential $(\varepsilon)$ that was calculated according to Helmholtz-Smoluchowsky from their electrophoretic mobility. Zeta potential was determined by a Zetasizer (Zetasizer Nano ZS, Malvern Instruments, UK) with a field strength of $20 \mathrm{~V} / \mathrm{cm}$ on a large bore measures cell. Before analysis, samples were diluted with $0.9 \% \mathrm{NaCl}$ to adjust the conductivity of $50 \mu \mathrm{S} / \mathrm{cm}$ [14]. Particle size, size distribution, and zeta potential the prepared formulation was performed at the SAIL, School of Pharmaceutical Sciences, Rajiv Gandhi Proudyogiki Viswavidyalaya, Bhopal (MP), India.

\section{Shape and surface morphology}

The shape and surface morphology were examined by Transmission electron microscopy and scanning electron microscopy (SEM). For the SEM analysis, the prepared NLCs were sprinkling on a double adhesive tape which was stuck on an aluminum stub. The stubs were then coated with a gold layer about $300 \AA$ of thickness using a sputter coater. The photomicrographs of prepared NLCs were taken with SEM (FESEM, GeminiO, Giess, Netherlands).

The shape of the NLCs was determined by Transmission Electron Microscopy (TEM; Philips CM12 Electron Microscope, Eindhoven, Netherlands). For the TEM, the samples were prepared by taking one drop NLCs dispersion and a copper grid was placed on it. After 60 seconds the grid was removed and excess of liquid was soaked with filter paper. Then the grid was negatively stained with $2.0 \%$ phosphotungstic acid solution at a $20 \mathrm{kV}$ acceleration voltage. The TEM images of prepared NLCs were taken which was shown in fig. 2(a) and 2(b). Analysis of sample on SEM and TEM was carried out at IISER, Bhopal, India [14-16].

\section{Determination of entrapment efficiency (EE)}

The entrapment efficiency of prepared NLCs was determined according to Gupta et al., (2007) [14]. The lyophilized formulation equivalent to $10 \mathrm{mg}$ of drug was taken and dissolved in $50 \mathrm{ml}$ of a beaker containing $10 \mathrm{ml}$ of ethanol. The solution was then centrifuged at $10000 \mathrm{rpm}$ for $10 \mathrm{~min}$. The $1.0 \mathrm{ml}$ of the supernatant solution was withdrawal with the help of micropipette and transfer into a $10 \mathrm{ml}$ of volumetric flask. The volume was made upto $10 \mathrm{ml}$ with ethanol and analyze spectroscopically for drug content using Simadzu 1700 UV-spectrophotometer and it was calculated according to the formula given below.

$\%$ Drug entrapment $=\frac{\text { Theoretical drug content }- \text { Practical drug content }}{\text { Theoretical drug content }} \times 100$

\section{Characterization of NLCs containing gel}

\section{Measurement of viscosity}

Viscosity measurements of prepared topical NLCs based gel were measured by Brookfield viscometer using spindle no. 63 with the optimum speed of 10rpm; viscosity was found to be $3776 \mathrm{cps}$.

\section{Drug content}

Accurately weighed equivalent to $100 \mathrm{mg}$ of topical NLCs gel was taken in a beaker and added $20 \mathrm{ml}$ of $0.01 \mathrm{~N} \mathrm{HCl}$. This solution was mixed thoroughly and filtered using Whatman filter paper no.1. Then $1.0 \mathrm{ml}$ of filtered solution was taken in $10 \mathrm{ml}$ capacity of volumetric flask and volume was made up to $10 \mathrm{ml}$ with $0.01 \mathrm{~N} \mathrm{HCL}$ [16]. This solution was analyzed using UV-Spectroscope at $\lambda_{\max } 251$ $\mathrm{nm}$. Drug content of NLCs based gel is shown in table 1 .

\section{Extrudability study}

Extrudability was based upon the quantity of the gel extruded from the collapsible tube on the application of a certain load. More the quantity of gel extruded shows better extrudability. It was determined by applying the weight on the gel-filled collapsible tube and recorded the weight on which gel was extruded from the tube. Extrudability of gel required 170 grams of weight to extrude a 0.6 $\mathrm{cm}$ ribbon of gel in 6 seconds [13].

\section{Spreadability?}

Spreadability of the formulation is necessary to provide sufficient dose available to absorb from the skin to get a good therapeutic response. It was determined by the method reported by Khan et al., (2013) [15]. An apparatus in which a slide fixed on a wooden block and the upper slide has movable and one end of movable slide tied with weight pan. To determine spreadability, placing $2-5 \mathrm{~g}$ of gel between two slides and gradually weight was increased by adding it on the weight pan and time required by the top plate to cover a distance of $10 \mathrm{~cm}$ upon adding $80 \mathrm{~g}$ of weight was noted. Good spreadability show lesser time to spread $[13,15]$

$$
\text { Spreadibility }(\mathrm{g} . \mathrm{cm} / \mathrm{sec})=\frac{\text { Weight tied toUpper Slide } \times \text { Lenth moved on the glass slide }}{\text { Time taken } \text { to slide }}
$$

\section{In vitro drug diffusion study}

The in vitro diffusion study is carried by using Franz Diffusion Cell. Egg membrane is taken as a semi-permeable membrane for diffusion. The Franz diffusion cell has a receptor compartment with an effective volume of approximately $60 \mathrm{ml}$ and an effective surface area of permeation 3.14sq. cms. The egg membrane is mounted between the donor and the receptor compartment. A two $\mathrm{cm}^{2}$ size patch taken and weighed then placed on one side of the membrane facing the donor compartment. The receptor medium is phosphate buffer $\mathrm{pH}$ 7.4. The receptor compartment is surrounded by a water jacket so as to maintain the temperature at $32 \pm 0.5{ }^{\circ} \mathrm{C}$. Heat is provided using a thermostatic hot plate with a magnetic stirrer. The receptor fluid is stirred by Teflon coated magnetic bead which is placed in the diffusion cell [5]. During each sampling interval, samples are withdrawn and replaced by equal volumes of fresh receptor fluid on each sampling. The samples withdrawn are analyzed spectrophotometrically at a wavelength of the drug (fig. 2)

\section{Stability studies}

Stability study was carried out for drug-loaded NLCs at two different temperatures i.e. refrigeration temperature $\left(4.0 \pm 0.2{ }^{\circ} \mathrm{C}\right)$ and at room temperature $\left(25-28 \pm 2{ }^{\circ} \mathrm{C}\right)$ for $3 \mathrm{w}$. The formulation subjected to stability study was stored in borosilicate container to avoid any interaction between the formulation and glass of container. The formulations were analyzed for any physical changes and drug content (table 2) [16].

\section{Cell culture and $\mathrm{mtt}$ assay}

Cell cytotoxicity assay (MTT assay) for the optimized formulation was performed using B16F10 skin cancer (melanoma) cells lines from Advanced Centre for Treatment, Research and Education in Cancer (ACTREC), Tata Memorial Hospital (TMH), Mumbai, Cancer 
cells were cultured in RPMI 1640 medium and added 10\% of FBS, and $100 \mathrm{~g} / \mathrm{ml}$ of streptomycin at $37{ }^{\circ} \mathrm{C}$ into $\mathrm{CO} 2$ incubator. After reaching $70 \%$ convergence cells were seeded in a 96 well microplate with $1000 \mu \mathrm{l}$ of growth medium. The prepared samples of the plain drug and optimized formulation of NLCs were added in the 96 well plates in order to increase the concentration of Docetaxel then cells were incubating for $24 \mathrm{hr}$. After incubation, $200 \mu \mathrm{l}$ of fresh media containing $20 \mu \mathrm{l}$ of MTT solution was added and then incubated it for $4 \mathrm{hr}$ at $37^{\circ} \mathrm{C}$. After incubation, media was replaced with $200 \mu \mathrm{l}$ of DMSO to dissolve Formazan crystals. The 96 well plate was analyze using microplate reader by taking absorbance at $570 \mathrm{~nm}$ [5].

\section{Cell uptake assay}

\section{Preparation of fluorescein isothiocyanate loaded NLCs}

NLCs formulation containing fluorescent label (with fluorescein isothiocyanate (FITC)) were prepared to add $0.04 \%$ of FITC in place of the drug to the lipid. The fluorescent NLCs were prepared according to the method used for the preparation of docetaxelloaded NLCs $[6,7]$.

\section{Fluorescence microscopy}

Qualitative Cellular uptake of conjugates was determined with the following procedure. Briefly, the optimized formulation was previously labeled with fluorescein isothiocyanate (FITC) solution. $2.5 \times 10^{5}$ cells/well were seeded in a six-well plate and incubated for $24 \mathrm{~h}$ at $37{ }^{\circ} \mathrm{C}$ with $5 \% \mathrm{CO}_{2}$, and then the medium in each well was replaced with $2 \mathrm{ml}$ of medium containing labeled formulation and plain FITC. The fluorescence due to the uptake of the fluorescentlabeled formulation was analyzed under an inverted fluorescent microscope (Labomed, Germany) after 4, 12, 24, and $48 \mathrm{~h} \mathrm{[5].}$

\section{RESULTS AND DISCUSSION}

Prepared formulations of NLCs were optimized on the basis of particle size, shape, surface charge, and entrapment efficiency. The particle size of NLCs determined by the light scattering method (Malvern Zetasizer, ZEM 5002, and UK) and found that the average particle size of optimized formulation was $178.37 \pm 5.07 \mathrm{~nm}$. The PDI was found 0.189 and Zeta potential was- $17.3 \pm 2.4$ (table 1) $[14,16,17]$. It was observed that the particles size of NLCs was increase with increasing the concentration of stearic acid and similarly particle size was decease with increasing the concentration of tween 80, stirring speed and increasing the sonication time. The size reduction may be due to surfactant action of surfactant, mechanical force and sonication wave force was responsible respectively for reducing the size of particles [18]. There was no significant difference in average particle size was observed with increasing the drug concentration. But in increasing the sonication time the size particle was decreasing from $218.42 \pm 6.09$ to $145.29 \pm 7.80$ after $90 \mathrm{sec}$ of sonication. The low PDI value represents the uniformity of formulation in which there is no major difference in the size of particles. The PDI of optimized formulation was found at 0.189. PDI of the formulation was varied with increasing or decreasing the concentration ratio of lipid and surfactant and sonication time [16]. It was observed that when the lipid ratio in formulations was decreased and surfactant concentration was increased then the PDI was found decrease. When, sonication time increase from 30 to 90 second, then PDI was $0.309,0.189$ and 0.487 , respectively for different NLCs formulations. It was observed that on 90 second of sonication time the PDI was increased and it was due to the high mechanical forced of sonication waves which were resultant in heat generation which leads to agglomerates or denaturing the lipid molecules after breaking the particles [19-22].

Table 1: Characterization of optimized formulation of NLCs

\begin{tabular}{lllll}
\hline Characterization & Average vesicle size $(\mathrm{nm})$ & \% Entrapment efficiency & PDI & Zeta potential (mV) \\
\hline Doce-NLCs & $178.3 \pm 5.07$ & $71.3 \pm 2.49$ & 0.189 & $-17.3 \pm 2.4$ \\
\hline
\end{tabular}

Value represent as mean $\pm \mathrm{SD}(\mathrm{n}=6)$

The shape and surface morphology of prepared NLCs was determined by using TEM and SEM. The photomicrograph was taken which shown in fig. 1 and was found that they were spherical in shape with smooth in the surface. The \% Entrapment efficiency of optimized NLCs formulation was found $71.03 \pm 2.49 \%[16]$.

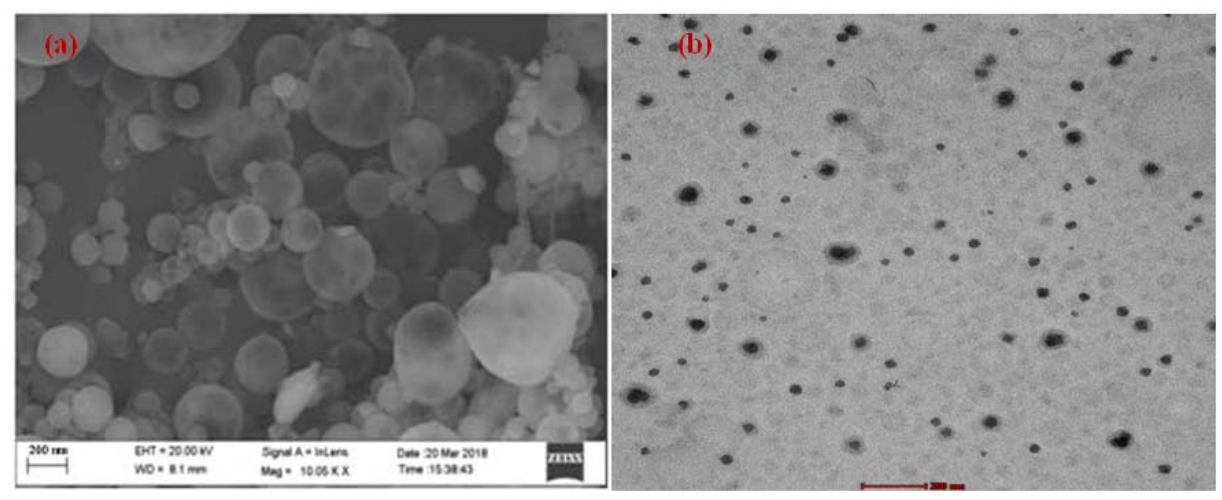

Fig. 1: SEM (a) and TEM (b) photomicrograph of optimized NLCs formulation at 1000KX

It was observed that the percent drug entrapment was decreasing with increasing the concentration of surfactant and on increasing the time of sonication. It is due to the extract out the drug from particles on increasing the mechanical force by sonication and size reduction of size NLCs on increasing the concentration of surfactant due to their surfactant action [16, 23-26]. Stability study data was revealed that the optimized formulation stable after 3 mo of storage at $4^{\circ} \mathrm{C}$ while at 25 $28 \pm 2{ }^{\circ} \mathrm{C}$, the formulation was found unstable. Stability of formulation was observed on the basis of \% drug remain, average particles size and physical appearance. The average particle size of NLCs was found $178.37 \pm 5.07,179.32 \pm 2.49$ and $186.84 \pm 5.84 \mathrm{~nm}$ after 1,2 and 3 mo of storage at $4.0 \pm 0.2{ }^{\circ} \mathrm{C}$ while at $25-28 \pm 2{ }^{\circ} \mathrm{C}$ the average particle size was found $192.56 \pm 3.43,238.54 \pm 4.87$ and $583.54 \pm 6.99 \mathrm{~nm}$ after 1,2 and 3 mo of storage. Drug remaining in NLCs formulation was $48.62 \pm 1.39$ $35.29 \pm 1.08$ and $23.83 \pm 2.11 \%$ after 1,2 and 3 mo of storage at 25$28 \pm 2{ }^{\circ} \mathrm{C}$ while there were no significant changes in \% drug remains and physical appearance in NLCs formulation was observed after 3 mo of storage at $4^{\circ} \mathrm{C}$. (table 2). 
Table 2: Stability study of optimized formulation of NLCs

\begin{tabular}{|c|c|c|c|c|c|c|}
\hline \multirow[t]{2}{*}{ Characteristic } & \multicolumn{6}{|l|}{ Time (mo) } \\
\hline & $1 \mathrm{mo}$ & & $2 \mathrm{mo}$ & & $3 \mathrm{mo}$ & \\
\hline Temperature & $4.0 \pm 0.2^{\circ} \mathrm{C}$ & $25-28 \pm 2{ }^{\circ} \mathrm{C}$ & $4.0 \pm 0.2^{\circ} \mathrm{C}$ & $25-28 \pm 2{ }^{\circ} \mathrm{C}$ & $4.0 \pm 0.2^{\circ} \mathrm{C}$ & $25-28 \pm 2{ }^{\circ} \mathrm{C}$ \\
\hline Average particle size $(\mathrm{nm})$ & $178.3 \pm 5.07$ & $192.5 \pm 3.43$ & $179.32 \pm 2.49$ & $238.5 \pm 4.87$ & $186.8 \pm 5.84$ & $583.5 \pm 6.99$ \\
\hline$\% \mathrm{EE}$ & $67.3 \pm 2.52$ & $48.6 \pm 1.39$ & $62.3 \pm 2.52$ & $35.2 \pm 1.08$ & $52.3 \pm 2.52$ & $23.8 \pm 2.11$ \\
\hline Physical Appearance & Normal & High turbid & Normal & $\begin{array}{l}\text { High turbid and } \\
\text { agglomeration }\end{array}$ & Normal & $\begin{array}{l}\text { High turbid and } \\
\text { agglomeration }\end{array}$ \\
\hline
\end{tabular}

Value represents as mean \pm SD $(n=6)$

Prepared gel was evaluated for viscosity, \% entrapment, extrudability, spreadability, and drug release study. It was found that viscosity of prepared gel was $178.37 \pm 5.07$ cps, \% Entrapment efficiency was $71.03 \pm 2.49 \%$, Extrudability was $170 \mathrm{~g}$ and Spreadability (g. $\mathrm{cm} / \mathrm{sec}$ ) was found that 5.16 (g. $\mathrm{cm} / \mathrm{sec}$ ) respectively (table 2 ).

Table 3: Characterization of gel-based formulation of NLCs

\begin{tabular}{lllll}
\hline Characterization & $\begin{array}{l}\text { Viscosity } \\
\text { (cps) }\end{array}$ & $\begin{array}{l}\text { \% Entrapment } \\
\text { efficiency }\end{array}$ & Release after 72 h & $\begin{array}{l}\text { Extrudability } \\
\text { (g) }\end{array}$ \\
\hline $\begin{array}{l}\text { Optimized formulation } \\
\text { (DOCE-NLCs) }\end{array}$ & 3776 & $71.03 \pm 2.49$ & $61.6 \pm 3.2$ & 170 \\
\hline
\end{tabular}

Value represents as mean $\pm \mathrm{SD}(\mathrm{n}=6)$ ?

In vitro drug release from NLCs was carried out using Frenze diffusion cell method and found $61.6 \pm 3.2 \%$ in $72 \mathrm{hr}$. In the first 30 min, it was $12.45 \pm 0.9 \%$ drug release which slightly high. It was due to the release of free drug present in the bag after leaching from NLCs [27-29]. Drug release from NLCs formulation was found in a very sustained and controlled manner and follow Higuchi and Korsmeyer Peppas release kinetic. Drug release in $24 \mathrm{hr}$ was $41.36 \pm 1.8$ and $52.06 \pm 2.6$ in $48 \mathrm{hr}$ (fig. 2).

In vitro cell line study data shown that Docetaxel loaded NLCs was entered by the cancer cells and retard the growth by killing them in very low concentrations [6]. In vitro cytotoxicity using B16F10 was evaluated for plain docetaxel and docetaxel-loaded NLCs formulations in the concentration range of $0.05-0.5 \mu \mathrm{M}$ of docetaxel. However, docetaxel and docetaxel-loaded NLCs showed 28.3 \pm 0.3 and $39.3 \pm 1.3$ growth inhibition respectively after $48 \mathrm{~h}$ upon incubation at $0.5 \mu \mathrm{g} / \mathrm{ml}$ concentration (fig. 7.2). This was due to the high penetration of docetaxel-loaded NLCs into cancer cells. The value of IC $_{50}$ for docetaxel and docetaxel-loaded NLCs was found to be $0.2 \mu \mathrm{g} / \mathrm{ml}$ and $0.1 \mu \mathrm{g} / \mathrm{ml}$ following $24 \mathrm{hr}$ and $48 \mathrm{hr}$ incubation, respectively which was more than 5 -fold lower as compared to free docetaxel (fig. 3).

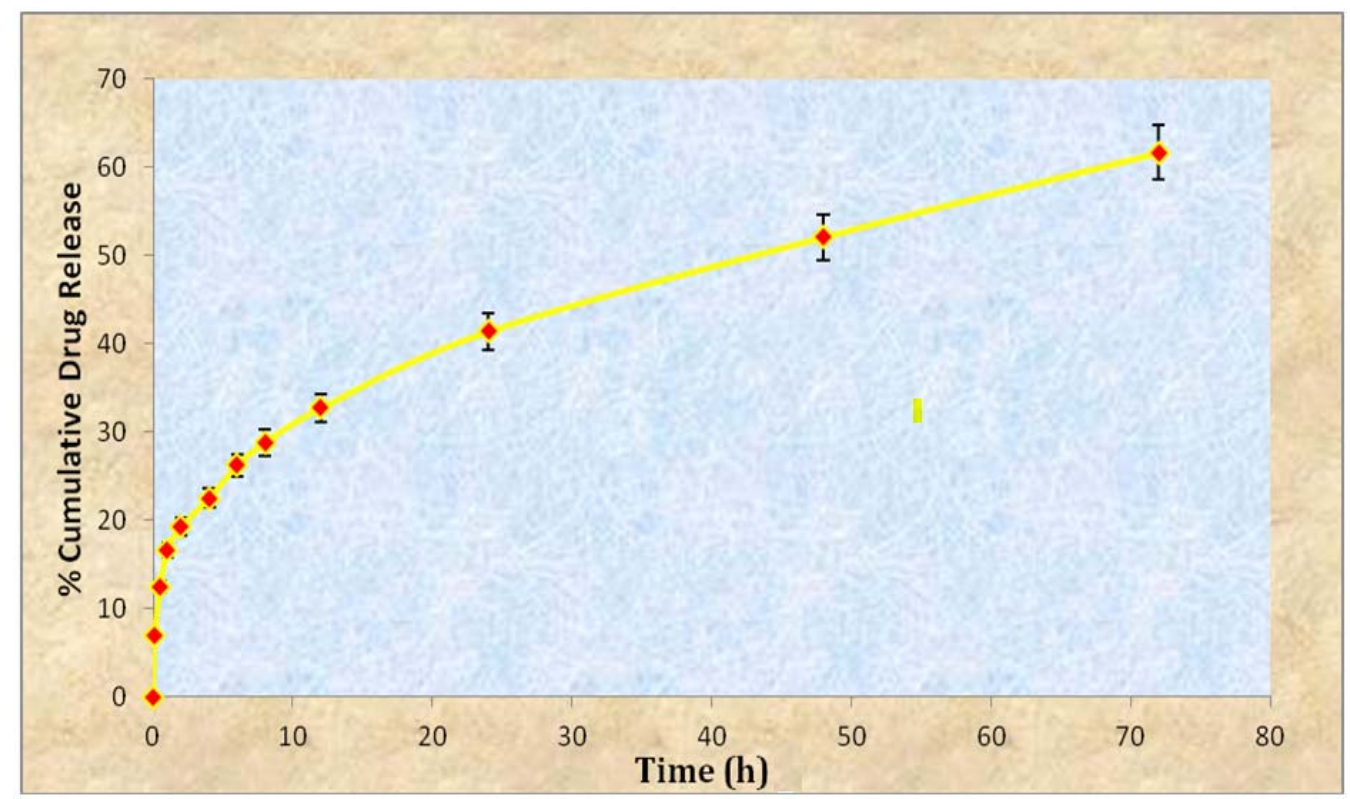

Fig. 2: In vitro drug release of gel-based NLCs, the value represents as mean $\pm S D(n=6)$

Qualitative (Fluorescence) uptake study of FITC and FITC loaded NLCs was performed to assess the capability of NLCs to penetrate skin cancer cell lines. Similar to the results of the percent cell growth inhibition assay, uptake studies also displayed higher uptake of
NLCs in comparison to plain FITC (fig. 4). Uptake of FITC loaded NLCs by cancer cells showed an enhanced uptake of the fluorescent marker after $4 \mathrm{hr}$ of incubation. A slight uptake was observed with the cell treated with free FITC [6-8]. 


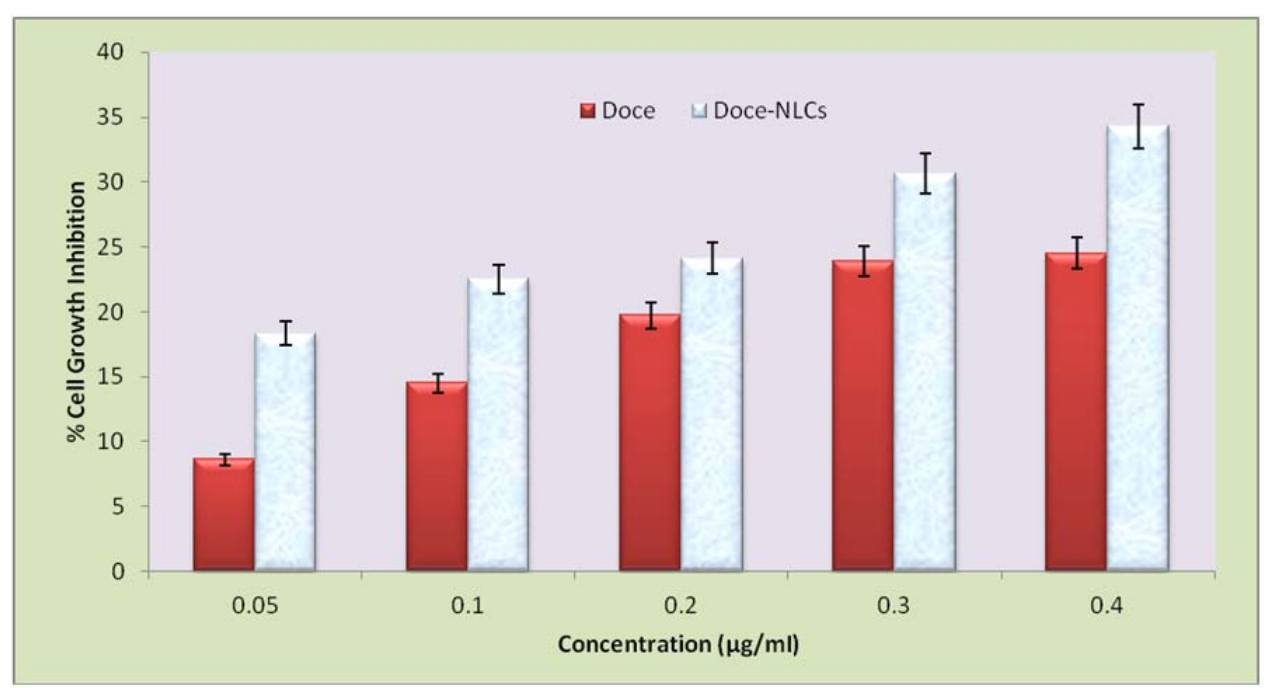

Fig. 3: In vitro cytotoxicity of DOCE and DOCE-NLCs formulations (Percent Cell Growth Inhibition Assay) on skin cancer cell line, the value represents as mean $\pm S D(n=6)$
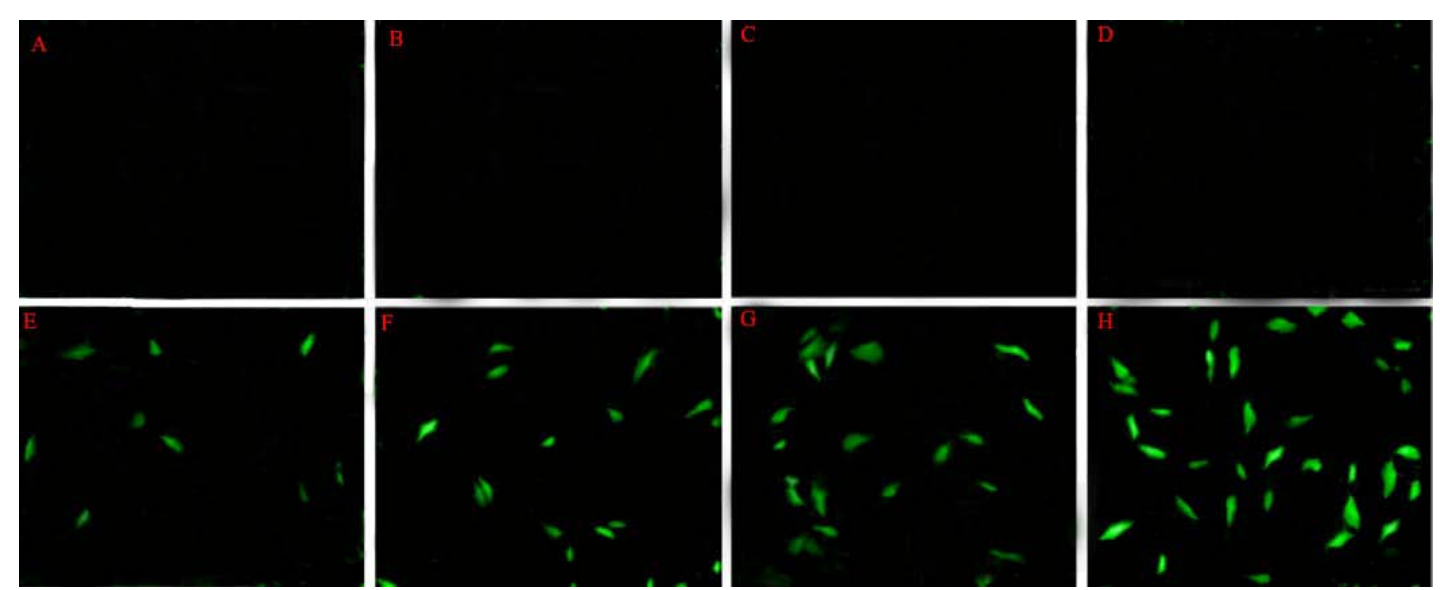

Fig. 4: Cell uptake (fluorescence microscopy) image of the plain drug (A-D) and Docetaxel loaded NLCs (E-H) after 4, 12, 24 and $28 \mathrm{~h}$ of incubation respectively

\section{Statistical analysis}

Data are expressed as the mean $\pm \mathrm{SD}$ and statistical analysis was carried out using one-way ANOVA test using the Graph Pad PRISM software. A value of $P<0.005$ was measured, which was statistically significant $[16,29]$.

\section{CONCLUSION}

We have demonstrated that NLCs are promising colloidal Nanosystems for dermal delivery of Docetaxel through the in vitro and in vivo studies. NLCs suspension enhances Docetaxel permeability and picks it up to cancer cells and decreases cell viability at different concentration. According to cell uptake study, a substantial improvement in the restriction of cancer cell was found. Further studies are necessary for the determination of long-term Docetaxel-NLCs stability and the lack of cytotoxicity on the various untargeted organs to exploit this carrier can be used for the treatment of skin cancer.

\section{ACKNOWLEDGMENT}

Authors want to acknowledge Sun Pharma. Pvt Ltd for providing the gift sample of Docetaxel. We are sincerely grateful to Dr. Ahmad Yari Khosroshahi for providing the necessary structure for the successful accomplishment of this research. One of the authors wants to acknowledge IISER Bhopal to provide electron microscopy facility. Authors also want to acknowledge Anti-Cancer Drug Screening
Facility (ACDSF), ACTREC, Tata Memorial Centre Kharghar, Navi Mumbai to perform cell line study. Authors want to acknowledge Department of Pharmaceutics, Ravishankar College of Pharmacy, Bhopal for providing freeze drying facility.

\section{DISCLOSURE STATEMENTS}

The authors report no declarations of interest

\section{AUTHORS CONTRIBUTIONS}

All the author have contributed equally

\section{CONFLICT OF INTERESTS}

Declaration for confirming the absence of any conflict of interest. We, the undersigned, Mrs. Arti Majumdar, Principle Investigator, and Dr. Nidhi Dubey and Dr. Nitin Dubey Co-Investigator of research article entitled "Dermal Delivery of Docetaxel Loaded Nano Liquid Crystals for the Treatment of Skin Cancer" submitting the article. We confirm that we do not have any conflict of interest in connection to the proposed research project and we have not granted, sought, attempted to obtain or accept any advantage, financial or in-kind, either directly or indirectly, as an incentive or reward relating to the award.

\section{REFERENCES}

1. Majumdar AJ, Dubey N. Formulation of paclitaxel-loaded nanostructured lipid carriers to study the effect of 
concentration of liquid lipids on drug release. J Drug Delivery Ther 2017;7:26-8.

2. Han Y, Li Y, Zhang P. Nanostructured lipid carriers as a nove drug delivery system for lung cancer gene therapy. Pharm Dev Technol 2016;21:277-81.

3. Majumdar A, Dubey N, Malviya N. Nanostructure lipid carriers: a promising tool for drug delivery in the treatment of skin cancer. Asian J Pharm Clin Res 2019;12:15-26.

4. Shao Z, Shao J, Tan B. Targeted lung cancer therapy: preparation and optimization of transferrin-decorated nanostructured lipid carriers as novel nanomedicine for codelivery of anticancer drugs and DNA. Int J Nanomed 2015;10:1223.

5. Tupal A, Sabzichi M, Ramezani F, Kouhsoltani M, Hamishehkar H. Dermal delivery of doxorubicin-loaded solid lipid nanoparticles for the treatment of skin cancer. J Microencapsul 2016;33:372-80.

6. Kong G, Barun RD, Dewhirst MW. Hyperthermia enables tumorspecific nanopartic1es delivery and effect of particle size. Cancer Res 2000;60:4440-6.

7. Leamon CP, Low PS. Selective targeting of malignant cells with cytotoxin-folate conjugates. J Drug Target 1994;2:101-12.

8. Li Y, Ogris M, Wagner E, Pelisek L, Ruffer M. Nanoparticles bearing polyethyleneglycol-coupled transferrin as gene carriers: preparation and in vitro evaluation. Int J Pharm 2003;259:93-101.

9. Lu Y, Low PS. Folate targeting of haptens to cancer cell surfaces mediates immunotherapy of syngeneic murine tumors. Cancer Immunol Immunother 2002;51:153-62.

10. Peracchia MT, Desmaele D, Couvreur P, d'Angelo J. Synthesis of a novel poly (MePEG cyanoacrylate-co-alkyl cyanoacrylate) amphiphilic copolymer for nanoparticle technology. Macromolecules 1997;30:846-51.

11. Jiang H, Pei L, Liu N. Etoposide-loaded nanostructured lipid carriers for gastric cancer therapy. Drug Delivery 2016;23:1379-82.

12. Selvamuthukumar S, Velmurugan R. Nanostructured lipid carriers: a potential drug carrier for cancer chemotherapy. Lipids Health Disease 2012;11:1.

13. Khan AW, Kotta S, Ansari SH, Sharma RK, Kumar A, Javed A. Formulation development, optimization and evaluation of aloe vera gel for wound healing. Pharmacogn Mag 2013:9:S6-S10.

14. Gupta Y, Jain A, Jain SK. Transferrin-conjugated solid lipid nanoparticles for enhanced delivery of quinine dihydrochloride to the brain. J Pharm Pharmacol 2007;59:1-6.

15. Patel K, Solanki N, Solanki S. Nanostructured lipid carrier-a novel drug delivery. J Pharm Sci Biosci Res 2015;5:385-92.
16. Shilpi S, Vimal VD, Soni V. Assessment of lactoferrin-conjugated solid lipid nanoparticles for efficient targeting to the lung. Prog Biomater 2015;4:55-3.

17. Shilpi S, Khatri K. Gold nanoparticles as carrier (s) for drug targeting and imaging. Pharm Nanotechnol 2015;3:154-70.

18. Chourasia MK, Jain SK. Design and development of multiparticulate system for targeted drug delivery to the colon. Drug Delivery 2004;11:201-7.

19. Kandav G, Bhatt DC, Jindal DK. Formulation and evaluation of allopurinol loaded chitosan nanoparticles. Int J Appl Pharma 2019;11:49-2.

20. Elgindy NA, Mehanna MM, Mohyeldin SM. Self-assembled nanoarchitecture liquid crystalline particles as a promising carrier for progesterone transdermal delivery. Int J Pharm 2016;501:167-79.

21. Mokashi AA, Gaikwad SL. Formulation and evaluation of liquisolid compacts of lornoxicam. Int J Pharm Pharm Sci 2019;11:33-7.

22. Abousamra MM, Mohsen AM. Solid lipid nanoparticles and nanostructured lipid carriers of tolnaftate: design, optimization and in vitro evaluation. Int J Pharm Pharm Sci 2016;8:380-5.

23. Gardouh AR, Faheim SH, Nouh AT, Ghorab MM. Influence of formulation factors on the size of nanostructured lipid carriers and nanoemulsions prepared by high shear homogenization. Int J Pharm Pharm Sci 2018;10:61-75.

24. Remya PN, Damodharan N. Formulation, development, and characterization of cilnidipine loaded solid lipid nanoparticles. Asian J Pharm Clin Res 2018;11:120-12.

25. Clayton KN, Salameh JW, Wereley ST, Kinzer Ursem TL. Physical characterization of nanoparticle size and surface modification using particle scattering diffusometry. Biomicrofluidics 2016;10:054107.

26. Shilpi S, Shivvedi R, Gurnany E, Chimaniya P, Singh A, Chouhan $\mathrm{M}$, et al. Chondroitin sulphate mediated targeted delivery of methotrexate and aceclofenac to the joints for effective management of rheumatoid arthritis. Afr J Pharm Pharmacol 2019;5:495-502.

27. Masarudin MJ, Cutts SM, Evison BJ, Phillips DR, Pigram PJ. Factors determining the stability, size distribution, and cellular accumulation of small, monodisperse chitosan nanoparticles as candidate vectors for anticancer drug delivery: application to the passive encapsulation of ${ }^{14} \mathrm{C}$-doxorubicin. Nanotechnol Sci Appl 2015;8:67-80.

28. Purkayastha HD, Hossian SKI. Nanosuspension: a modern technology used in the drug delivery system. Int J Curr Pharm Res 2019;11:1-3.

29. Arunkumar N, Deecaraman M, Rani C. Nanosuspension technology and its applications in drug delivery. Asian J Pharm 2009;9:168-73. 